\title{
Distribution of new satellites and simple sequence repeats in annual and perennial Glycine species
}

\author{
Hsuan Chen ${ }^{1,2}$, Mei-Chu Chung ${ }^{1}$, Yuan-Ching Tsai ${ }^{1}$, Fu-Jin Wei ${ }^{1}$, Jaw-Shu Hsieh² and Yue-le C. Hsing ${ }^{\text {* }}$
}

\begin{abstract}
The repeat sequences occupied more than $50 \%$ of soybean genome. In order to understand where these repeat sequences distributed in soybean genome and its related Glycine species, we examined three new repeat sequences-soybean repeat sequence (SBRS1, SBRS2 and SBRS3), some nonspecific repeat sequences and 45S rDNA on several Glycine species, including annual and perennial accessions in this study. In the annual species, G. soja, signals for SBRS1 and ATT repeat can be found on each chromosome in GG genome, but those for SBRS2 and SBRS3 were located at three specific loci. In perennial Glycine species, these three SBR repeat frequently co-localized with $45 S$ rDNA, two major $45 \mathrm{~S}$ rDNA loci were found in all tetraploid species. However, an extra minor locus was found in one accession of the G. pescadrensis (Tab074), but not in another accession (Tab004). We demonstrate that some repetitive sequences are present in all Glycine species used in the study, but the abundancy is different in annual or perennial species. We suggest this study may provide additional information in investigations of the phylogeny in the Glycine species.
\end{abstract}

Keywords: Glycine, FISH, SSRs, 45S rDNA, Repeat sequence, Chromosome markers

\section{Background}

Soybean (Glycine max L. Merrill) is the most important legume crop because of its economic value and biological features for research. Since soybean seed consists of high protein and oil contents, it has become one of the most important food crops for human and livestock, as well as a valuable resource for biofuel energy. Improving soybean varieties has been slow and limited because of the lack of genetic diversity (Keim et al. 1990; Krishnan et al. 2001). Wild germplasm may be a significant breeding resource for current varieties that have undergone several genetic bottlenecks and have shown limited genetic variability (Hyten et al. 2006; Keim et al. 1990). These wild germplasm harbor many traits of interest to soybean breeders, such as biotic and abiotic disease resistance (Newell and Hymowitz 1975), high seed protein content (Sebolt et al.

\footnotetext{
*Correspondence: bohsing@gate.sinica.edu.tw

${ }^{1}$ Institute of Plant and Microbial Biology, Academia Sinica, Taipei 115,

Taiwan

Full list of author information is available at the end of the article
}

2000) and increased yield (Concibido et al. 2003). Thus, investigating Glycine species is important for soybean genetics and breeding.

There are around 30 species in Genus Glycine which had been classified into two subgenera, Soja and Glycine. The subgenus Soja $(2 \mathrm{n}=40)$ includes only G. $\max$ and its annual close related G. soja Sieb. and Zucc., which may intercross freely with soybean (Palmer et al. 1987; Singh and Hymowitz 1988). The subgenus Glycine contains all perennial species with various genome types and ploidies ( $2 \mathrm{n}=2 \mathrm{x}=40,2 \mathrm{n}=4 \mathrm{x}=80$ and some aneuploids) (Doyle et al. 2004; Grant et al. 1984; Newell and Hymowitz 1983; Singh and Hymowitz 1985). Early investigations of phylogenetic relationships in Glycine species based on their ability to produce fertile hybrids and the degree of meiotic chromosomes pairing (reviewed by Ratnaparkhe et al. 2011). This led to the designation of seven genome groups, i.e. reproductively compatible within species, while reproductively isolated from other genome groups (groups A to G, Singh and Hymowitz 1985; Hymowitz et al. 1998). Other data, including isozymes (Doyle et al.

\section{Springer}


1986) and DNA phylogenetic analyses (Doyle et al. 1990a, b, c; Kollipara et al. 1997), suggested hybrid fertility as the primary criterion to identify species to genome groups and resulted in the designation of two additional genome groups, $\mathrm{H}$ and $\mathrm{I}$. Besides, the situation in some species even more complicated, such as the G. tabacina and G. tomentella species complex, multiple separate 'races' are recognized that have not yet taxonomically arisen to species status, but that display enough molecular phylogenetic divergence from one another to be grouped into separate taxa (Doyle et al. 2004; Sherman-Broyles et al. 2014).

The Glycine species germplasm in Taiwan is abundant and important. Four species have been collected, including G. soja Siebold and Zucc. (GG genome, $2 n=40$ ), G. tomentella Hayata $\left(\mathrm{DDD}_{1} \mathrm{D}_{1}\right.$ genome, $\left.2 \mathrm{n}=80\right), \mathrm{G}$. dolichocarpa Tateishi and Ohashi $\left(\mathrm{A}_{6} \mathrm{~A}_{6} \mathrm{DD}\right.$ genome, $2 \mathrm{n}=80)$ and G. pescadrensis Hayata $\left(\mathrm{A}_{6} \mathrm{~A}_{6} \mathrm{~B}_{3} \mathrm{~B}_{3}\right.$ genome, $2 \mathrm{n}=80$ ) (Hsing et al. 1995, 2001; Tateishi and Ohashi 1992; Thseng et al. 1999; Tsai et al. 2001; Tsai 2006). G. soja is widely distributed in Russia, Korea, Japan, China and Taiwan (Singh and Hymowitz 1987), with Taiwan being the southernmost among these areas. The three wild perennial Glycine species, G. tomentella, G. dolichocarpa and G. pescadrensis, are found in Taiwan, the Ryukyu Islands, the Philippines, the South Pacific islands and Australia, with Taiwan being the northernmost of these areas (Hymowitz et al. 1998). All the remaining perennial Glycine species are found only in Australia (Tindale and Craven 1988). Therefore, the Ryukyu Islands, Taiwan, and its adjacent islands are unusual because they have representatives of both subgenera of Glycine. The collection and study of Glycine species in Taiwan and its adjacent islands thus provide information for better understanding the evolution and relationships between these two subgenera (Hsieh et al. 2001).

The soybean genome has been well documented as paleopolyploidy and manifested as allopolyploid diploidy (Gill et al. 2009; Mudge et al. 2005; Schlueter et al. 2007; Shoemaker et al. 1996; Tek et al. 2010). In addition, whole-genome sequencing (Williams 82) and resequencing projects on Glycine species were available recently (Jackson et al. 2006; Katayose et al. 2012; Kim et al. 2010; Lam et al. 2010; Schmutz et al. 2010; Weidner et al. 2012). However, little information is available on the genome composition of wild relatives; that is, cytological research of wild soybean is still limited.

Fluorescent in situ hybridization (FISH) is a powerful tool for cytological studies. FISH used with specific markers can be used to label specific chromosomes and target given genomes or particular regions on chromosomes (Cheng et al. 2007; Jiang and Gill 2006; Kopecky et al. 2008; Pinkel et al. 1986). Furthermore, nonspecific repeats such as simple repeat sequences (SSRs) may also be used as genomic and chromosomal markers among many species (Cuadrado et al. 2008; Cuadrado and Jouve 2007).

FISH has been used in cytological research on soybean. Several repeat sequences such as ribosomal RNA genes (rDNAs) (Shi et al. 1996), SB92 (Kolchinsky and Gresshoff 1995; Vahedian et al. 1995) and STR120 (Morgante et al. 1997) were labeled on soybean chromosomes and used in chromosome "painting" (Shi et al. 1996). FISH with bacterial artificial chromosome (BAC) clones used as probes suggested heterochromatic blocks on the chromosome pericentromeric region (Lin et al. 2005), and some research has provided evidence of chromosomelevel homeology in the paleopolyploid soybean genome (Pagel et al. 2004; Walling et al. 2006). In the study of soybean chromosome structure and genomic evolution, SB92 was previously suggested as a major repeat sequence in the G. max genome (Kolchinsky and Gresshoff 1995; Vahedian et al. 1995). Later, SB92 and its similar sequence SB91 were both defined as the centromere sequences of the GG genome by cytological features (Gill et al. 2009) and thus designated CentGm-1 (SB92) and CentGm-2 (SB91) (Tek et al. 2010). In addition, FISH revealed CentGm-1 or CentGm-2 present in about a half of all G. $\max$ chromosomes, which suggests allopolyploidy in the paleopolyploid genome (Gill et al. 2009). The G. max karyotyping system in mitotic metaphase was recently studied with a probe cocktail of BAC clones and partial centromere oligonucleotides (Findley et al. 2010), and this system has enabled the characterization of most of the chromosomal translocation lines (Findley et al. 2011).

The rDNAs have been widely used as reliable landmarks in chromosome karyotyping of several higher plants. In higher eukaryotes, the $45 \mathrm{~S}$ and $5 \mathrm{~S}$ rDNA loci are transcribed by different RNA polymerases and usually located in different positions on chromosomes (Srivastava and Schlessinger 1991). The number and location on chromosomes for both $45 \mathrm{~S}$ and $5 \mathrm{~S}$ may be diverse within related species (Chang et al. 2009; Chung et al. 2008; Pedrosa-Harand et al. 2006). In other words, karyotyping with rDNA loci may reflect the relationships of related species. Most of the recent cytological research on Glycine species has focused on the number of rDNA loci. The genome from diploid Glycine species, known as the paleopolyploidy, was predicted to consist of two $45 \mathrm{~S}$ rDNA loci because it was ancient allopolyploidy; however, only one locus was observed on diploid Glycine species (Krishnan et al. 2001; Singh et al. 2001). Therefore, one $45 \mathrm{~S}$ rDNA locus disappeared during soybean genome diploidization, whereby the ancient tetraploid became a new diploid paleopolyploidy. 
Some studies revealed two 5S rDNA and two 45S rDNA loci in most allotetraploid genomes (Krishnan et al. 2001; Singh et al. 2001); however, an extra minor $45 \mathrm{~S}$ rDNA locus was found in only two allotetraploid species (Krishnan et al. 2001). Therefore, the number of $45 \mathrm{~S}$ loci among Glycine species or accessions was not as simple as the model of "diploid-doubled to tetraploid" of one locus for diploid and two loci for tetraploid species (Krishnan et al. 2001; Singh et al. 2001).

In the current study, we investigated the difference in repeat sequences between soybean and its wild related species. Here, we report three new soybean repeat sequences-SBRS1, SBRS2 and SBRS3-isolated from the soybean WSG data. In light of their distribution on chromosomes of GG genome, the three repeat sequences may be considered as FISH karyotyping markers for GG genome. We also labeled the three sequences in some wild Glycine species and found that they widely co-localized with $45 \mathrm{~S}$ rDNA.

\section{Methods}

\section{Plant materials}

Glycine species used and locations where they were collected are in Table 1 along with their genome types and known USDA permanent plant introduction (PI) numbers or IL number designated by Dr. T. Hymowitz. All plant materials were previously described in detail (Hsieh et al. 2001). Cultivated soybean Shi-shi was kindly provided by Kaohsiung District Agricultural Research and Extension Station. Glycine species distributed in Taiwan and nearby islands were collected by Drs. J. S. Hsieh and Y. C. Huang, Department of Agronomy, National Taiwan University. Three diploid Glycine tomentella accessions originally from Papua New Guinea and Australia were kindly provided by Dr. T. Hymowitz, Department of Crop
Science, University of Illinois, USA. These plants were grown in the greenhouse at Academia Sinica, Taiwan. Root tips of seedling were used for metaphase chromosome preparation.

\section{Flow cytometry for estimating ploidy}

Flow cytometric estimation of nuclear DNA content involved the MoFlo XDP Cell Sorter (Beckman Coulter, Fullerton, CA, USA), with propidium iodide (PI) as the fluorescent stain. A total of $20 \mathrm{mg}$ of young leaves of each plant and standard nuclear fractions were prepared and mixed. Chicken erythrocyte nuclei (CEN; BioSure Inc., Grass Valley, CA, USA) and rainbow trout erythrocyte nuclei (TEN; NPE Systems Inc, Pembroke Pines, FL, USA) were used as internal standards and the DNA index (Vindelov et al. 1983). Leaf samples were chopped by using of a razor in a Petri dish containing $0.5 \mathrm{ml}$ extraction buffer (Partec CyStain PI Absolute P Nuclei Extraction Buffer; Partec GMBH, Munster, Germany). The resulting extract was passed through two $30-\mu \mathrm{m}$ filters before the addition of $0.5 \mathrm{ml}$ Partec CyStain PI Absolute P Staining Buffer. Samples were kept in the dark for up to 30 min before flow cytometry. Six thousand cells were counted in each sample, with three replicates. The predicted genome size was calculated by assuming that $1 \mathrm{pg}$ DNA $=965$ Mbp (Bennett et al. 2000).

\section{Predictions of repeat sequences in the soybean genome}

Candidate repeat sequences were identified on the basis of the soybean WGS data (Schmutz et al. 2010). "eTandem" in EMBOSS 6.0 was used to scan all scaffold sequences, and the outputs were filtered by shell scripts and AWK script in Linux with repeat unit length $>70 \mathrm{bp}$, homologous identity $>70 \%$ and copies $>30$. The longest

Table 1 The accessions of the Glycine species used in this study, with their nuclear DNA content and collection locations

\begin{tabular}{|c|c|c|c|c|c|c|}
\hline \multirow[t]{2}{*}{ Species } & \multirow[t]{2}{*}{ Genome types } & \multicolumn{2}{|c|}{ Accession numbers } & \multicolumn{2}{|c|}{$2 C$ DNA content } & \multirow[t]{2}{*}{ Collection location } \\
\hline & & $\mathrm{TW}^{\mathrm{a}}$ & IL or $\mathrm{PI}^{\mathrm{c}}$ & $\mathrm{PG}^{\mathbf{b}}$ & Mbp $^{b}$ & \\
\hline G. $\max$ & GG & Shi-shi & PI416967 & $2.44 \pm 0.01$ & 2360 & Cultivar \\
\hline G. soja & GG & Soja001 & PI393551 & $2.00 \pm 0.02$ & 1930 & Shimen, Taoyuan, Taiwan \\
\hline G. syndetika & $\mathrm{A}_{6} \mathrm{~A}_{6}$ & Tom052 & PI441000 & $2.58 \pm 0.00$ & 2490 & North Queensland, Australia \\
\hline G. tomentella & $\mathrm{DD}$ & Tom062 & PI446993 & $2.11 \pm 0.01$ & 2040 & Papua New Guinea \\
\hline G. tomentella & $\mathrm{D}_{1} \mathrm{D}_{1}$ & Tom051 & PI505301 & $2.24 \pm 0.10$ & 2170 & West Australia \\
\hline G. pescadrensis & $A_{6} A_{6} B_{3} B_{3}$ & Tab004 & IL875 & $4.52 \pm 0.02$ & 4370 & Houliao, Penghu, Taiwan \\
\hline G. pescadrensis & $A_{6} A_{6} B_{3} B_{3}$ & Tab074 & - & $4.90 \pm 0.03$ & 4730 & Kingmen, Taiwan \\
\hline G. dolichocarpa & $\mathrm{A}_{6} \mathrm{~A}_{6} \mathrm{DD}$ & Tom039 & PI320548 & $5.17 \pm 0.05$ & 4990 & Tungho, Taitung, Taiwan \\
\hline G. tomentella & $\mathrm{DDD}_{1} \mathrm{D}_{1}$ & Tom034 & IL872 & $5.18 \pm 0.21$ & 5000 & Daguang, Pintung, Taiwan \\
\hline
\end{tabular}

a Accession number in our laboratory

b 1 pg DNA = $965 \mathrm{Mbp}$ (Bennett et al. 2000), $\mathrm{N}=3$

c Illinois (IL) numbers or USDA Plant introduction (PI) numbers 
repeats were used for primer design (Additional file 1: Table S1).

\section{Syntheses of probes for FISH analysis}

To prepare probes for FISH analysis, the pTA71 plasmid that contains a 9.1-kb fragment of $18 \mathrm{~S}-5.8 \mathrm{~S}-26 \mathrm{~S}$ rDNA from common wheat (Gerlach and Bedbrook 1979) was labeled with biotin-16-dUTP by nick translation (Roche Diagnostics, Penzberg, Germany). Other repeat sequences were subcloned into pGEM-T Easy vector (Promega) by using Shi-shi genomic DNA and were labeled with digoxigenin-11-dUTP by using the Roche PCR DIG Probe synthesis kit (Roche).

\section{Southern blot analysis}

Genomic DNA $(30 \mu \mathrm{g})$ of each Glycine accession was completely digested with restriction enzymes (EcoRI or NdeI, New England Biolabs) before separation by electrophoresis overnight on a $0.8 \%$ agarose gel in $0.5 \mathrm{X}$ TBE buffer, then blotting onto Hybond-N+ nylon membranes (Amersham Pharmacia Biotech). Probe preparation, membrane hybridization, and signal detection followed the instructions of the ECL direct nucleic acid labeling and detection system (Amersham Pharmacia Biotech).

\section{Chromosome preparation and FISH analysis}

The terminal $0.5 \mathrm{~cm}$ of young roots was collected from individual seedlings, pretreated with $2 \mathrm{mM}$ 8-hydroxyquinoline for $2 \mathrm{~h}$ at room temperature and fixed overnight in Farmer's fixative [95\% ethanol + glacial acetic acid $(3: 1 \mathrm{v} / \mathrm{v})]$. The fixed root tips were washed with distilled water before incubation in a cell wall digestive enzyme mixture of $6 \%$ pectinase (Sigma Chemical, St. Louis, MO, USA) and $6 \%$ cellulase (Onozuka R-10; Yakult Honsha, Tokyo, Japan) in $75 \mathrm{mM} \mathrm{KCl}(\mathrm{pH}=4.0)$ buffer at $37^{\circ} \mathrm{C}$ for $1.5-3 \mathrm{~h}$ depending on the characteristics of each accession.

After a wash with distilled water, the terminal $1 \mathrm{~mm}$ of softened tissues was squashed on a slide (Chang et al. 2009). Samples were pretreated with pepsin $(1.25 \mathrm{mg} /$ $\mathrm{ml}$ for G. soja, $5 \mathrm{mg} / \mathrm{ml}$ for other accessions, in $10 \mathrm{mM}$ $\mathrm{HCl})$ at $37^{\circ} \mathrm{C}$ for 3 to $8 \mathrm{~h}$ depending on the characteristics of each accession. FISH analysis was performed as described previously (Chung et al. 2008).

\section{Results}

\section{Estimation of genome size}

The DNA contents of the Glycine species were analyzed by flow cytometry (Table 1). The estimated 2C DNA contents of the diploid species, cultivated soybean Shi-shi (Glycine max, GG genome), Soja001 (Glycine soja, GG genome), Tom052 (Glycine syndetike, $\mathrm{A}_{6} \mathrm{~A}_{6}$ genome), Tom062 (Glycine tomentella, DD genome), and Tom051
(Glycine tomentella, $\mathrm{D}_{1} \mathrm{D}_{1}$ genome), were 2360, 1930, 2500, 2040 and $2170 \mathrm{Mb}$, respectively, and contents varied between different species by $29 \%$. The estimated 2C DNA contents of the tetraploid species, Tab 004 ( $G$. pescadrensis, $\mathrm{A}_{6} \mathrm{~A}_{6} \mathrm{~B}_{3} \mathrm{~B}_{3}$ genome), Tab 074 (G. pescadrensis, $\mathrm{A}_{6} \mathrm{~A}_{6} \mathrm{~B}_{3} \mathrm{~B}_{3}$ genome), Tom039 (Glycine dolichocarpa, $\mathrm{A}_{6} \mathrm{~A}_{6} \mathrm{DD}$ genome) and Tom034 (Glycine tomentella, $\mathrm{DDD}_{1} \mathrm{D}_{1}$ genome), were $4370,4730,4990$ and $5000 \mathrm{Mb}$, respectively, and differed between different species or accessions by $15 \%$. The DNA for two G. pescadrensis accessions, Tab 004 and Tab 074, was collected from Penghu and Kingmen islands, respectively and the content differed by $9 \%$. When compare the tetraploid with its two diploid parental species, the DNA content of G. dolichocarpa (Tom039) is higher than the total DNA content from G. syndetike (Tom052) and G. tomentella (Tom062), the DNA content of tetraploid G. tomentella (Tom034) is higher than the total DNA content from two diploid G. tomentella (Tom051 and Tom062).

\section{Repeat sequences from WGS data and the analysis}

To investigate the repeat sequence component in the Glycine genome, we used the WGS data to find new repeat sequences. We identified 17 candidate repeat sequences by bioinformatics analysis. Several of these candidates belong to the LTR120 family (Morgante et al. 1997) and SB92 family (Kolchinsky and Gresshoff 1995). Finally, we chose 3 new repeat sequences, designated soybean repeat sequence1 (SBRS1), SBRS2 and SBRS3; their sequences and designed primers are in Additional files 1 and 2.

\section{SBRS1}

A 48 bp minisatellite sequence, represents approximately 131,000 copies in the WGS data; 123,000 copies were aligned into 13 pseudomolecules, including $\mathrm{Gm1}, 2$, 3, 5, $11,12,14,15,16,17,18,19$ and 20 . The remaining copies were aligned into contigs. SBRS1 is a head-to-tail tandem repeat with tens to hundreds of copies in each region.

\section{SBRS2}

A 124 bp minisatellite sequence, represents approximately 6000 copies in the WGS data. About $95 \%$ of the SBRS2 repeats were aligned into pseudomolecules. The SBRS2 is a head-to-tail tandem repeat with usually less than 10 copies in each continguous region and is dispersed on all of the 20 pseudomolecules in the WSG data. The most significant region rich in SBRS2 was located at $\mathrm{Gm} 9$, where 1095 copies of the SBRS2 clustered in a 270-kb region.

\section{SBRS3}

A 201 bp minisatellite sequence, represents 8206 copies in the WGS data; 8016 copies were aligned into pseudomolecules. It is also a tandem repeat, with usually less 
than 10 copies in each region, dispersed on all 20 pseudomolecules. Three regions especially contain a high density of SBRS3 repeats, including 2 on Gm14 (1512 copies were separated into 2 groups $26,000 \mathrm{~kb}$ apart) and the other one on Gm20 (400 copies clustered together).

To understand the existence and the distribution of these three repeat sequences in the Glycine genome, we used them as probes in Southern blot analyses with genomic DNA of the cultivated soybean and the collected Glycine species. All three repeats, SBRS1, SBRS2 and SBRS3, showed heavy ladder signals in the GG genome species, G. max and G. soja (Lanes 1-4 of Fig. 1; Additional file 3: Figure S1, Additional file 4: Figure S2). These heavy ladder signals are similar between G. max and G. soja, but the patterns among the three repeat sequences are different. However, the 3 repeat sequences showed single band and the similar size in other genome species, including G. tomentella, G. dolichocarpa and G. pescadrensis, a 3.8- and a 9-kbp band were found in EcoRI- and $N d e$-digested DNA samples, respectively, of all perennial Glycine species tested (Lanes 5-12 of Fig. 1. Additional file 3: Figure S1, Additional file 4: Figure S2). Therefore, the three repeat sequences exist in each Glycine species tested, with high copies in GG genome, but with very low copies in other species.

\section{FISH analysis with SBRS1, SBRS2, SBRS3 and 45S rDNA}

FISH analysis was used in further evaluated the distribution of the three repeat sequences in the genome of

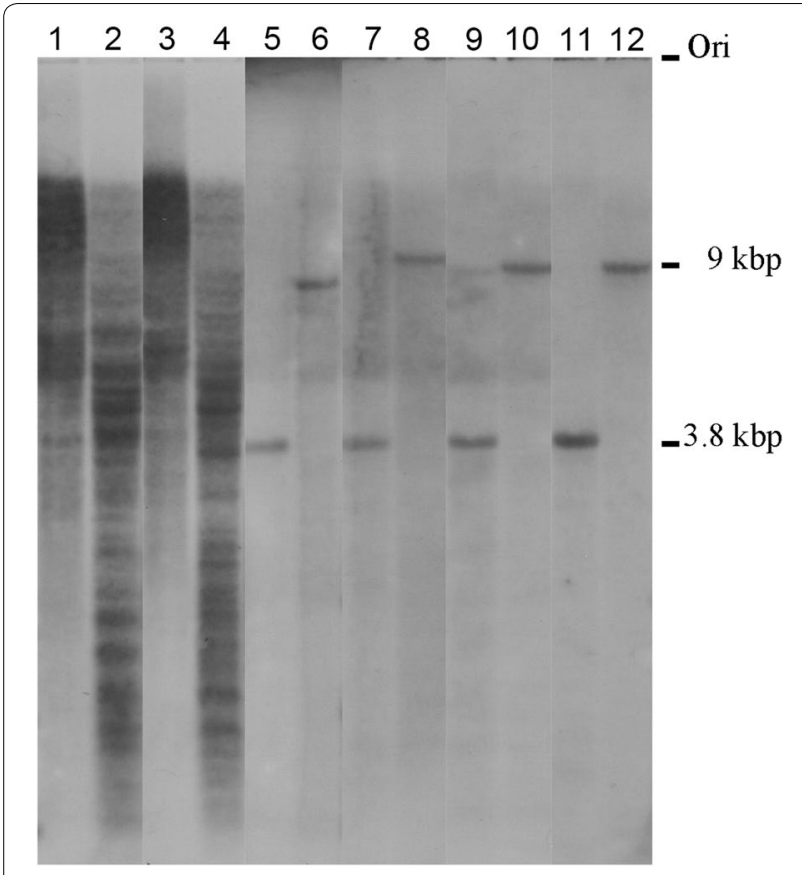

Fig. 1 Southern blot analysis of the SBRS1 on Glycine species
Glycine species. We used the root tips of G. soja to represent the GG genome on FISH analysis because the cultivated soybean and G. soja both represent the GG genome, and band patterns on Southern blot analysis were similar (Fig. 1, Additional file 3: Figure S1, Additional file 4: Figure S2). The $45 \mathrm{~S}$ rDNA probe was used as a control, and it was located at the distal ends of one pair of chromosomes of G. soja (Fig. 2a, green).

SBRS1 signals were dispersed on every chromosome of G. soja as shown by metaphase (Panel A) and interphase (Panel B) chromosomes (Fig. 2a, red). Throughout the genome, the distribution of SBRS1 signals varied among chromosomes. SBRS2 signals were detected as clusters on two pairs of chromosomes of G. soja (Fig. 3). FISH signals for one of the SBRS2 clusters overlapped with $45 \mathrm{~S}$ rDNA at the distal ends of one pair of chromosomes (Fig. 3a, yellowish green), and the second SBRS2 cluster was detected in the proximal regions of another pair of chromosomes (Fig. 3a, b, red). SBRS3 signals were detected on three pairs of chromosomes of G. soja (Fig. 4, red), and none overlappped with 45S rDNA (Fig. 4, green). One of the SBRS3 signals was detected at the subdistal ends of one pair of chromosomes, and the other 2 were detected in the proximal regions and the distal ends of another pair of chromosomes.

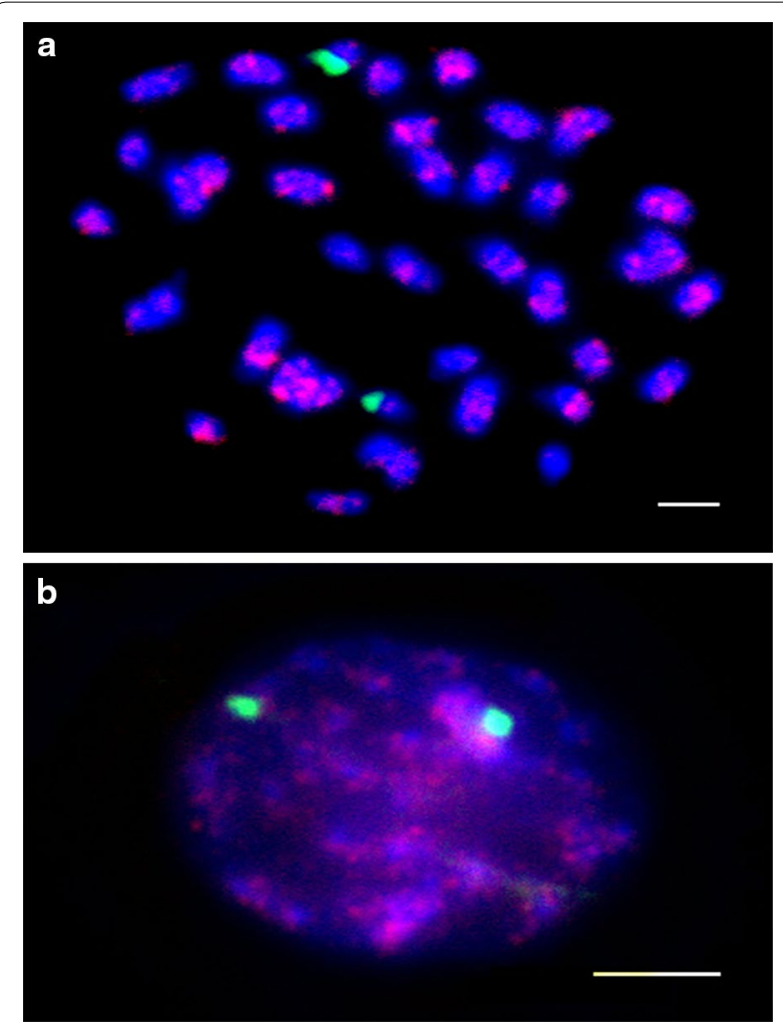

Fig. 2 FISH analysis of SBRS1 and 45S rDNA on G. soja chromosomes 


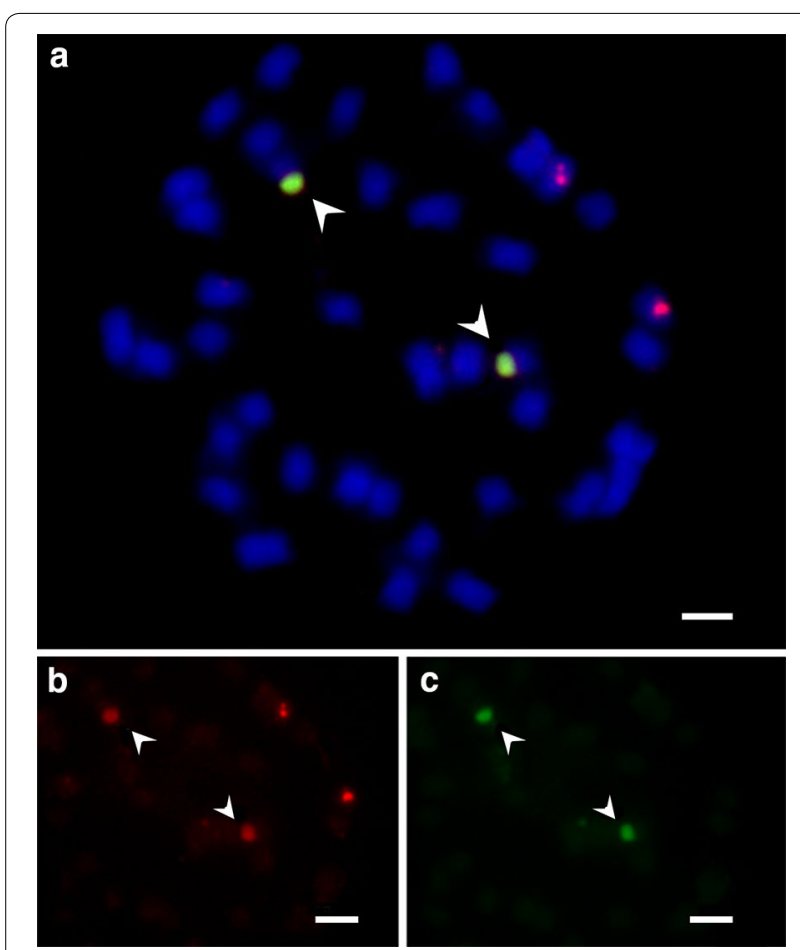

Fig. 3 FISH analysis of SBRS2 and 45S rDNA on G. soja chromosomes

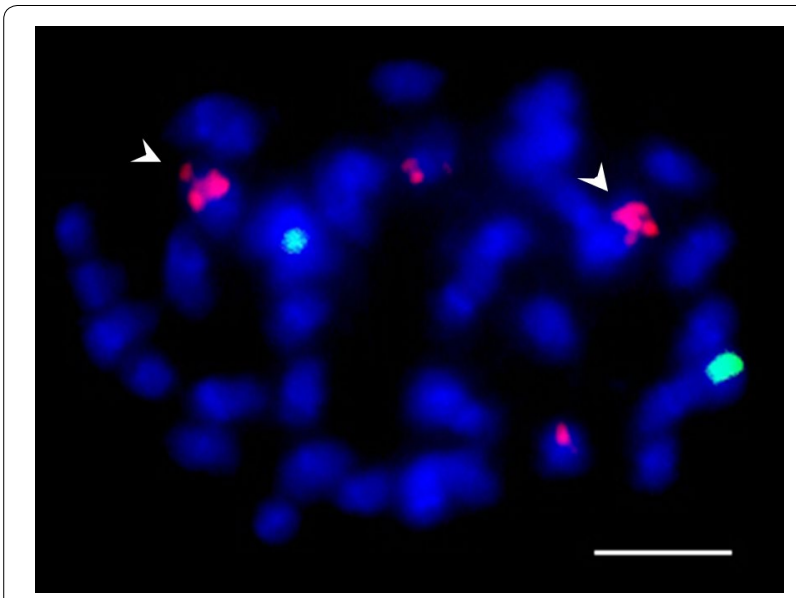

Fig. 4 Localization of SBRS3 and 45S rDNA on G. soja mitotic chromosomes

We labeled probes of the three repeat sequences and 45S rDNA in allotetraploid Glycine species (i.e., Tom034, Tom039 and Tab 004; Fig. 5), and their diploid relatives (i.e., Tom052, Tom062 and Tom051; Additional file 5: Figure S3; Additional file 6: Figure S4, Additional file 7: Figure S5, Additional file 8: Figure S6). Most of the three tandem repeat sequences signals co-localized with $45 \mathrm{~S}$ rDNA signals among the tetraploid and diploid relatives tested (Figs. 3, 5; Additional file 5: Figure S3, Additional file 6: Figure S4, Additional file 8: Figure S6). SBRS1 and SBRS3 signals did not co-localize with 45S rDNA signals in the 2 diploid genomes, GG genome (Figs. 2, 4) or DD genome (Additional file 7: Figure S5, Additional file 8: Figure S6). In the genome of Tom062 (DD genome), very weak SBRS1 signals located on many chromosomes (Additional file 7: Figure S5), SBRS2 signals co-localized with 45S rDNA (Additional file 8: Figure S6), and no substantial SBRS3 signal was detected. In addition, all tetraploid accessions showed two $45 \mathrm{~S}$ rDNA loci, with a minor signal detected in the proximal regions of another pair of chromosomes of Tab 074 (Fig. 6). FISH analysis results are summarized in Table 2.

\section{FISH analysis with SSR probe in Glycine species}

We additionally used 5 types of SSR probes (i.e., ATT, AT, CAA, CT and CTT) in FISH analysis. However, only one SSR probe, with 33 copies of the repeat ATT, on G. soja, gave interesting results, and, similar to SBRS1, ATT signals were detected as dispersed signals on every chromosomes of the GG genome (Fig. 7, red). There was no ATT signal on the mitotic chromosomes of most other Glycine species except Tom034. Few very weak ATT probe signals were detected on this accession, but the signals were unstable. In addition, the signal distribution for these SSRs varied among chromosomes.

\section{Discussion}

\section{The predicted repeat sequences were confirmed} by cytological study

The soybean WGS sequence project has set significantly new milestones for understanding the soybean genome and its evolutionary history (Jackson et al. 2006; Schmutz et al. 2010). In the current study, we identified three new repeat sequences from soybean WGS data. Using bioinformatics, we propose their characterization in the soybean genome. We used WGS as a resource in chromosome marker design for the cultivated soybean and other Glycine species, and found that use of the WGS data was powerful for searching for candidates of repeat sequences and designing probes for cytological research.

For the GG genome, the WGS data could be used to predict general copy numbers of the repeat sequences in each cluster and the location of repeat-sequence condensed regions. FISH analyses confirmed these bioinformatics findings (Figs. 2, 3, 4; Table 2). WGS data may be also used in cytological research for the wild related species. Combining bioinformatics and cytological strategies may help bridge the gap between cultivated species and related species. In the current study, we analysis the three new repeat sequences on many Glycine species by FISH. Similar studies had shown that FISH analysis would reveal heterochromatin 

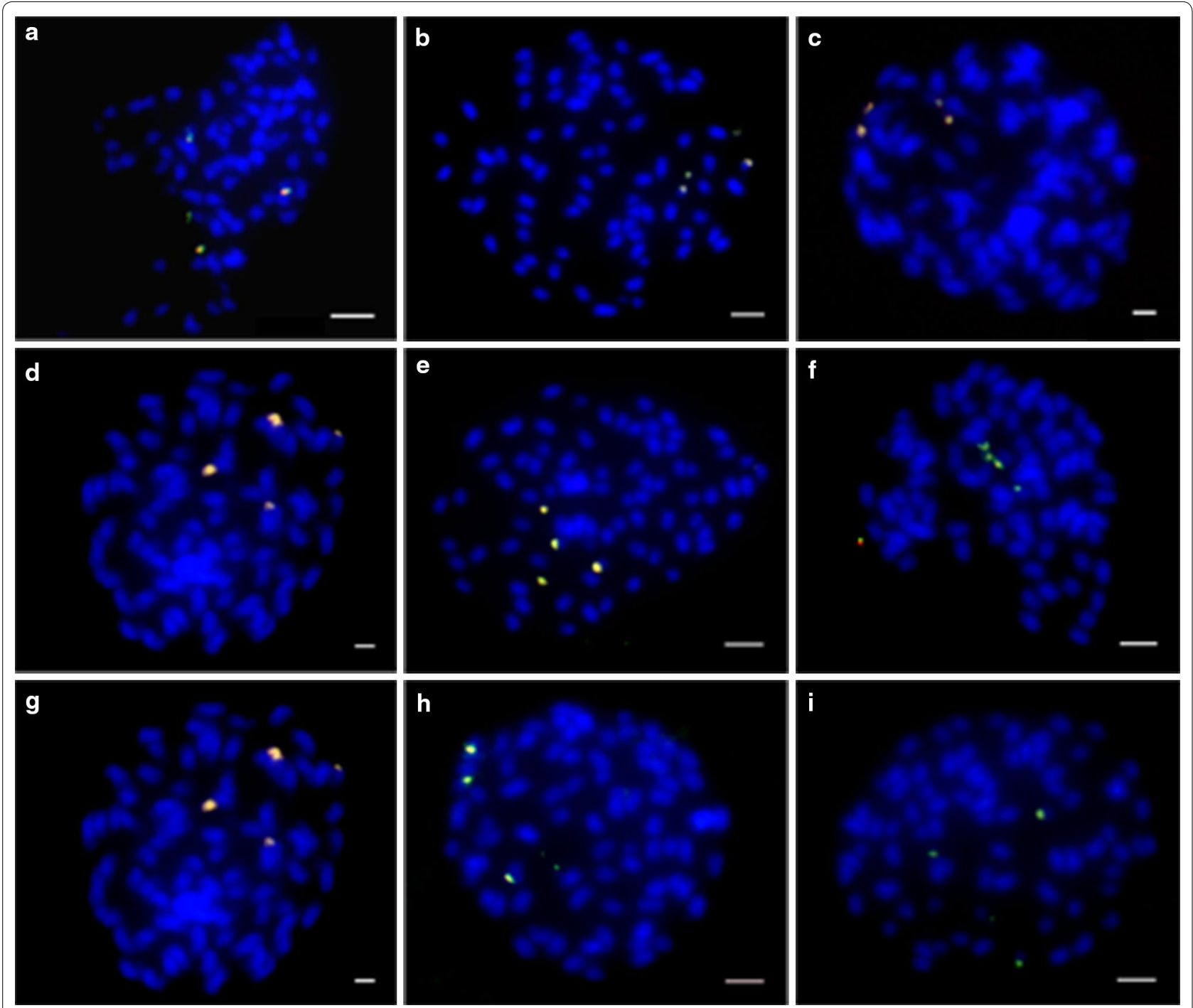

Fig. 5 Co-localization of the 3 repeat sequences and 45S rDNA on chromosomes of Glycine species

organization using the centromeric or satellite repeats (Ananiev et al. 1998 for maize; Badaeva et al. 1996 for Aegilops species; Kulikova et al. 2004 for Medicago species). Because Glycine species consist of high chromosome numbers $(38,40,78$, or 80 ; Hymowitz et al. 1998), as well, these chromosomes are compact and small, the utilization of repetitive sequences as probe for FISH analysis may help on the cytogenesis and breeding analysis in the post-genomics era.

\section{Possible evolutionary process for the three new repeat sequences among Glycine species}

Differences in the distribution of repetitive DNA sequences were shown between Glycine species in the current study (summarized in Table 2). The chromosomal localization of these DNA probes was different.
The possible association of the these repeat sequences and rDNA loci may be due to (1) the three repeat sequences having existed in the rDNA of the genome of their common earlier ancestor, (2) all having expanded and dispersed in GG genome, and finally (3) SBRS1 and SBRS3 being reduced or disappeared in $45 \mathrm{~S} \mathrm{rDNA}$ loci during the GG (Soja001) and DD (Tom062) genome evolution and SBRS2 still existing in the 45S rDNA of all tested Glycine species (Table 2). Dolye and his colleague used global, gene-specific, and relaxed clock methods to date the polyploid history of soybean and suggested the date for the G. $\max / G$. tomentella split averaged between 3.8 and 6.86 Mya across methods (Egan and Doyle 2010). It coincides well with the fact that the shared repeat sequences, but with different amount of such fragments, among the Glycine species. 


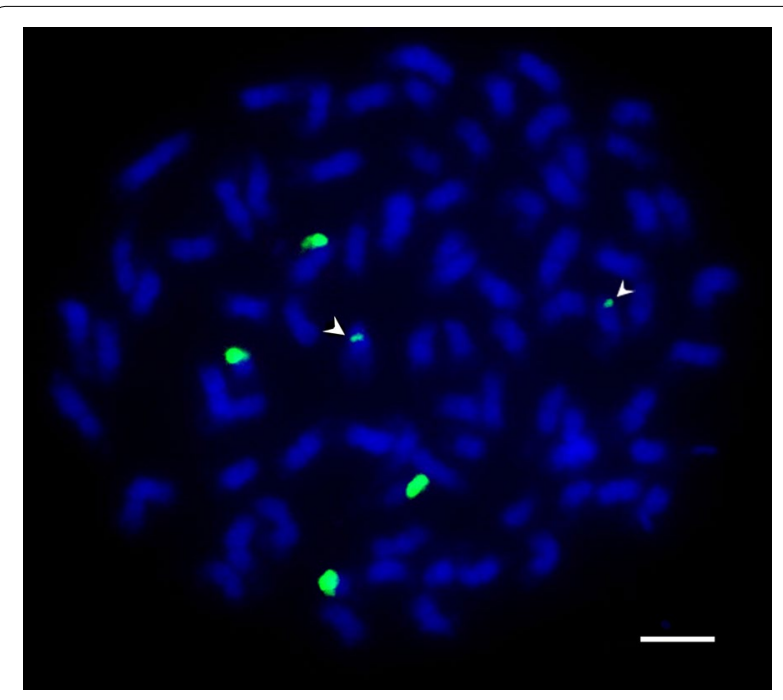

Fig. 6 FISH analysis of 45S rDNA on mitotic chromosomes of Tab074

Many satellite sequences are homologs to the IGS subrepeats of rDNA from other plants genome, such as legumes (Falquet et al. 1997), potato (Stupar et al. 2002), tobacco (Lim et al. 2004; Volkov et al. 1999) and tomato (Jo et al. 2009). In tomato study, the insertion of a retrotransposon into the rDNA gene enhanced the amplification of the nearby IGS subrepeats. Those amplified subrepeats then dispersed into other loci and became repeat sequences (Jo et al. 2009). Other studies also proposed that some transposon elements, such as En/Spmlike transposons, could be involved in rDNA movement and as one of the key steps when the rDNA subrepeat turned into repeat sequences (Raskina et al. 2004a, 2008; Schubert and Wobus 1985).

\section{Diversity of the genome in Glycine species}

We analyzed the DNA content of the nine Glycine accessions, five of them are diploid and another four are allotetraploid, by flow cytometry. The two G. pescadrensis accessions Tab 004 and Tab 074 collected from Penghu and Kingmen, differed in DNA content (Table 1). In addition, the DNA content of Soja001 and the cultivated soybean (GG genome) differs up to $22 \%$ (Table 1). The DNA content of G. dolichocarpa (Tom039) and G. tomentella (Tom034) are more than the sum of their two parental diploid species (Table 1).

Research using Helianthus (Ungerer et al. 2006) suggested that retrotransposons may play an important role in the genome expansion process of allotetraploid evolution. The dynamics of transposon element driven genome evolution have been reported for several plant genomes (El Baidouri and Panaud 2013). In fact, retrotransposons occupy the largest part of the cultivated soybean genome (Schmutz et al. 2010) and may play a role in Glycine genome size variations.

The number of $45 \mathrm{~S}$ rDNA loci among wild soybeans is dynamic. In previous studies, the number of $45 \mathrm{~S}$ rDNA loci among the tetraploid Glycine species was suggested to be the same (Krishnan et al. 2001; Singh et al. 2001). However, two major and one minor loci of $45 \mathrm{~S}$ rDNA signals were detected in Tab 074 (G. pescadrensis, $\mathrm{A}_{6} \mathrm{~A}_{6} \mathrm{~B}_{3} \mathrm{~B}_{3}$ genome). The minor signals are found on the middle area of a pair of the chromosomes. Only two major loci of $45 \mathrm{~S}$ rDNA were found for the other tetraploids, including Tab 004. These two G. pescadrensis accessions were collected from Penghu and Kingmen, and the distance between these two islands is about $140 \mathrm{~km}$, the geographical isolation may explain the diversity of $45 \mathrm{~S}$ rDNA loci. Thus,

Table 2 Summary of FISH analysis for soybean repeat sequence1 (SBRS1), SBRS2, and SBRS3, 45S rRNA and general ATT repeat

\begin{tabular}{|c|c|c|c|c|c|c|}
\hline Accessions & Genome & SBRS1 & SBRS2 & SBRS3 & $45 S$ & $\overline{\text { ATT }}$ \\
\hline Soja001 & GG & All & 2 and $1^{a}$ & 3 & 1 & $A \|^{b}$ \\
\hline Tom052 & $A_{6} A_{6}$ & $1^{\mathrm{a}}$ & $1^{\mathrm{a}}$ & $1^{\mathrm{a}}$ & 1 & ND \\
\hline Tom062 & $\mathrm{DD}$ & Manyc & Many ${ }^{\mathrm{a}, \mathrm{d}}$ & $N D^{d}$ & 1 & $N D$ \\
\hline Tom051 & $\mathrm{D}_{1} \mathrm{D}_{1}$ & $1^{\mathrm{a}}$ & $1^{\mathrm{a}}$ & $1^{\mathrm{a}}$ & 1 & ND \\
\hline Tab004 & $\mathrm{A}_{6} \mathrm{~A}_{6} \mathrm{~B}_{3} \mathrm{~B}_{3}$ & $2^{\mathrm{a}}$ & $2^{\mathrm{a}}$ & $2^{a}$ & 2 & ND \\
\hline Tab074 & $\mathrm{A}_{6} \mathrm{~A}_{6} \mathrm{~B}_{3} \mathrm{~B}_{3}$ & $2^{\mathrm{a}}$ & $2^{\mathrm{a}}$ & $2^{\mathrm{a}}$ & $3^{b}$ & ND \\
\hline Tom039 & $\mathrm{A}_{6} \mathrm{~A}_{6} \mathrm{DD}$ & $2^{\mathrm{a}}$ & $2^{\mathrm{a}}$ & $2^{a}$ & 2 & ND \\
\hline Tom034 & $\mathrm{DDD}_{1} \mathrm{D}_{1}$ & $2^{\mathrm{a}}$ & $2^{\mathrm{a}}$ & $2^{a}$ & 2 & $2-3$ \\
\hline
\end{tabular}

One locus has 2 signals on a set of chromosomes, and 2 loci have 4 signals

ND No significant signal detected on metaphase chromosome

a Signals co-localized with 455 rDNA

b 2 major and 1 minor signal

c Very weak signals

d Interphase data were used 


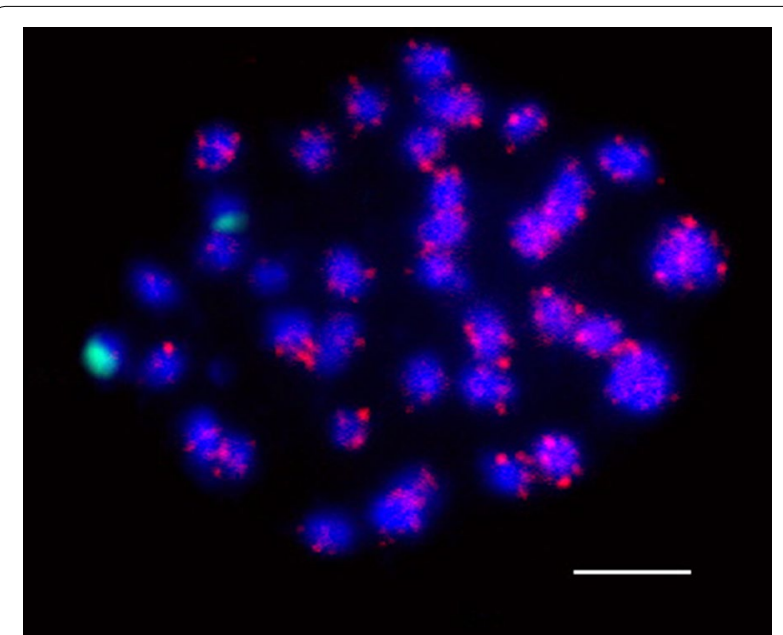

Fig. 7 Co-localization of the ATT probe and 45S rDNA on G. soja chromosomes

the evolution of the $45 \mathrm{~S}$ rDNA in the Glycine genome is more complex than the model of "diploid-doubled to tetraploid".

Variations in the $45 \mathrm{~S}$ rDNA loci among natural hybrids and related species were reported for Lycoris (Chang et al. 2009), Oryza (Chung et al. 2008), Triticeae (Kim et al. 1993), and Arabidopsis (Maluszynska and Heslopharrison 1993). As well, the ability to alter the number and location of rDNA loci among closely related species or even accessions was noted (Chung et al. 2008; Raskina et al. 2004b). In our study, the variation in number of rDNA loci in Glycine was more dramatic than in previous studies (Krishnan et al. 2001; Singh et al. 2001). Such differences in number or location of $45 \mathrm{~S}$ rDNA may be used as chromosome markers.

\section{Genome and chromosome markers of Glycine species}

Specific repeat sequences, such as SBRS1-3, and nonspecific repeat sequences, such as SSR and rDNA, may be potential genome or chromosome markers. The nonspecific repeat sequences can also be used as specific markers, if the distributions of repeats are different enough among genomes. For instance, the SSRs, which are widely identified among species (Varshney et al. 2005), have been used to label the chromosomes of different genomes in hexaploidy Triticum aestivum (Cuadrado et al. 2000, 2008). We use nonspecific repeat sequences as probes for labeling chromosomes of several Glycine species. Signals of ATT were exclusively detected on the GG genome, with no difference between G. soja and G. max (data not shown). Although 2-3, weak ATT signals could be detected on the chromosome of Tom034 (data not shown), they were easy to be separated from the strong ones of GG genome.
The study of the Glycine genome is important for soybean improvement; combing bioinformatics and cytology techniques can advance investigations. Our study is just a beginning to show that the soybean WSG data and cytological methods can be used to find new repeat sequences, reveal the genome evolution process, and provide addition information in investigation of the phylogeny in the Glycine species.

\section{Additional files}

Additional file 1. Table S1. Sequence of the primers used in the study.

Additional file 2. Table S2. Sequence of repeat sequences and probes used in the study.

Additional file 3. Figure S1. Southern blot analysis of SBRS2 on Glycine species.

Additional file 4. Figure S2. Southern blot analysis of SBRS3 on Glycine species.

Additional file 5. Figure S3. FISH analysis of SBRS and 45S rDNA on Tom051 chromosomes.

Additional file 6. Figure S4. FISH analysis of SBRS and 45S rDNA by FISH on Tom052 chromosomes.

Additional file 7. Figure S5. FISH analysis of SBRS1 and 45S rDNA on Tom062 chromosomes.

Additional file 8. Figure S6. FISH analysis of SBRS2 and $45 \mathrm{~S}$ rDNA on Tom062 chromosomes.

\section{Authors' contributions}

HC and MCC performed the FISH analysis, YCT and JSH collected the Glycine species and performed the genome size analysis, FJW performed the bioinformatics analysis, YIC wrote the manuscript. All authors read and approved the final manuscript.

\section{Author details}

${ }^{1}$ Institute of Plant and Microbial Biology, Academia Sinica, Taipei 115, Taiwan. 2 Department of Agronomy, National Taiwan University, Taipei 106, Taiwan.

\section{Acknowledgements}

We deeply thank the Kaohsiung District Agricultural Research and Extension Station for the Shi-shi seeds, Professor Hymowitz at University of Illinois for the three diploid G. tomentella seeds, and the Plant Cell Biology Core Lab in the Institute of Plant and Microbial Biology, Academia Sinica, for flow cytometry analysis. We also appreciate the technical support from Ms. Yu-Chu Chang and English editing from Ms. Laura Smales (BioMedEditing, Toronto, Canada). This research was supported by the National Science Council and Academia Sinica to $\mathrm{JSH}$ and $\mathrm{YICH}$.

\section{Competing interests}

The authors declare that they have no competing interests.

Received: 2 April 2015 Accepted: 17 August 2015

Published online: 16 September 2015

\section{References}

Ananiev EV, Phillips RL, Rines HW (1998) Chromosome-specific molecular organization of maize (Zea mays L.) centromeric regions. Proc Nat Acad Sci USA 95:13073-13078

Badaeva ED, Friebe B, Gill BS (1996) Genome differentiation in Aegilops. 1. Distribution of highly repetitive DNA sequences on chromosomes of diploid species. Genome 39:293-306 
Bennett, MD, Bhandol, P, Leitch IJ (2000) Nuclear DNA amounts in Angiosperms and their modern uses new estimates. Ann Bot 86:859-909

Chang Y-C, Shii C-T, Chung M-C (2009) Variations in ribosomal RNA gene loci in spider lily (Lycoris spp.). J Amer Soc Hort Sci 134:567-573

Cheng YY, Fang SA, Lin YC, Chung MC (2007) A repetitive sequence specific to Oryza species with BB genome and abundant in Oryza punctata Kotschy ex Steud. Bot Stud 48:263-272

Chung MC, Lee Yl, Cheng YY, Chou YJ, Lu CF (2008) Chromosomal polymorphism of ribosomal genes in the genus Oryza. Theor Appl Genet 116:745-753

Concibido VC, La Vallee B, Mclaird P, Pineda N, Meyer J, Hummel L, Yang J, Wu K, Delannay X (2003) Introgression of a quantitative trait locus for yield from Glycine soja into commercial soybean cultivars. Theor Appl Genet 106:575-582

Cuadrado A, Jouve N (2007) Similarities in the chromosomal distribution of $A G$ and $A C$ repeats within and between Drosophila, human and barley chromosomes. Cytogenet Genome Res 119:91-99

Cuadrado A, Schwarzacher T, Jouve N (2000) Identification of different chromatin classes in wheat using in situ hybridization with simple sequence repeat oligonucleotides. Theor Appl Genet 101:711-717

Cuadrado A, Cardoso M, Jouve N (2008) Physical organisation of simple sequence repeats (SSRs) in Triticeae: structural, functional and evolutionary implications. Cytogenet Genome Res 120:210-219

Doyle MJ, Grant JE, Brown AHD (1986) Reproductive isolation between isozyme groups of Glycine tomentella (Leguminosae), and spontaneous doubling of their hybrids. Aust J Bot 34:523-535

Doyle JJ, Doyle JL, Brown AH, Grace J (1990a) Multiple origins of polyploids in the Glycine tabacina complex inferred from chloroplast DNA polymorphism. Proc Nat Acad Sci USA 87:714-717

Doyle JJ, Doyle JL, Brown AHD (1990b) A chloroplast-DNA phylogeny of the wild perennial relatives of soybean (Glycine subgenus Glycine): congruence with morphological and crossing groups. Evolution 44:371-389

Doyle JJ, Doyle JL, Brown AHD (1990c) Chloroplast DNA polymorphism and phylogeny in the B genome of Glycine subgenus Glycine (Leguminosae). Amer J Bot 77:772-782

Doyle JJ, Doyle JL, Rauscher JT, Brown AHD (2004) Evolution of the perennial soybean polyploid complex (Glycine subgenus Glycine): a study of contrasts. Biol J Linn Soc 82:583-597

Egan AN, Doyle J (2010) A comparison of global, gene-specific, and relaxed clock methods in a comparative genomics framework: dating the polyploid history of soybean (Glycine max). Syst Biol 59:534-547

El Baidouri M, Panaud O (2013) Comparative genomic paleontology across plant kingdom reveals the dynamics of TE-driven genome evolution. Gen Biol Evol 5:954-965

Falquet J, Creusot F, Dron M (1997) Molecular analysis of Phaseolus vulgaris rDNA unit and characterization of a satellite DNA homologous to IGS subrepeats. Plant Physiol Bioch 35:611-622

Findley SD, Cannon S, Varala K, Du J, Ma J, Hudson ME, Birchler J, Stacey G (2010) A fluorescence in situ hybridization system for karyotyping soybean. Genetics 185:727-744

Findley SD, Pappas AL, Cui Y, Birchler JA, Palmer RG, Stacey G (2011) Fluorescence in situ hybridization-based karyotyping of soybean translocation lines. G3 (Genes/Genomes/Genetics 1:117-129

Gerlach WL, Bedbrook JR (1979) Cloning and characterization of ribosomal RNA genes from wheat and barley. Nucl Ac Res 7:1869-1885

Gill N, Findley S, Walling JG, Hans C, Ma J, Doyle J, Stacey G, Jackson SA (2009) Molecular and chromosomal evidence for allopolyploidy in soybean. Plant Physiol 151:1167-1174

Grant JE, Brown AHD, Grace JP (1984) Cytological and isozyme diversity in Glycine tomentella Hayata (Leguminosae). Aust J Bot 32:665-677

Hsieh JS, Hsieh KL, Tsai YC, Hsing YI (2001) Each species of Glycine collected in Taiwan has a unique seed protein pattern. Euphytica 118:67-73

Hsing YIC, Hsieh KL, Huang YC, Hsieh JS (1995) The relationships of cultivated soybeans and their wild relatives collected from Taiwan-revealed by seed proteins. Bot Bull Acad Sinica 36:65-72

Hsing YLC, Hsieh JS, Peng Cl, Chou CH, Chiang TY (2001) Systematic status of the Glycine tomentella and G. tabacina species complexes (Fabaceae) based on ITS sequences of nuclear ribosomal DNA. J Plant Res $114: 435-442$

Hymowitz T, Singh RJ, Kollipara KP (1998) The genomes of the Glycine. Plant Breed Rev 16:289-317
Hyten DL, Song Q, Zhu Y, Choi I-Y, Nelson RL, Costa JM, Specht JE, Shoemaker RC, Cregan PB (2006) Impacts of genetic bottlenecks on soybean genome diversity. Proc Nat Acad Sci USA 103:16666-16671

Jackson SA, Rokhsar D, Stacey G, Shoemaker RC, Schmutz J, Grimwood J (2006) Toward a reference sequencing of the soybean genome: a multiagency effort. Crop Sci 46:S55-S61

Jiang J, Gill BS (2006) Current status and the future of fluorescence in situ hybridization (FISH) in plant genome research. Genome 49:1057-1068

Jo S-H, Koo D-H, Kim J, Hur C-G, Lee S, Yang T-j, Kwon S-Y, Choi D (2009) Evolution of ribosomal DNA-derived satellite repeat in tomato genome. BMC Plant Biol 9:42

Katayose $Y$, Kanamori $H$, Shimomura M, Ohyanagi $H$, Ikawa $H$, Minami $H$, Shibata M, Ito T, Kurita K, Ito K, Tsubokura Y, Kaga A, Wu JZ, Matsumoto T, Harada K, Sasaki T (2012) DaizuBase, an integrated soybean genome database including BAC-based physical maps. Breed Sci 61:661-664

Keim P, Diers BW, Olson TC, Shoemaker RC (1990) RFLP mapping in soybean: association between marker loci and variation in quantitative traits. Genetics 126:735-742

Kim NS, Kuspira J, Armstrong K, Bhambhani R (1993) Genetic and cytogenetic analyses of the genome of Triticum-Monococcum.VIII. Localization of rDNAs and characterization of $5 \mathrm{~s}$ ribosomal-DNA genes. Genome 36:77-86

Kim MY, Lee S, Van K, Kim TH, Jeong SC, Choi IY, Kim DS, Lee YS, Park D, Ma J, Kim WY, Kim BC, Park S, Lee KA, Kim DH, Kim KH, Shin JH, Jang YE, Do Kim K, Liu WX, Chaisan T, Kang YJ, Lee YH, Kim KH, Moon JK, Schmutz J, Jackson SA, Bhak J, Lee SH (2010) Whole-genome sequencing and intensive analysis of the undomesticated soybean (Glycine soja Sieb. and Zucc.) genome. Proc Nat Acad Sci USA 107:22032-22037

Kolchinsky A, Gresshoff PM (1995) A major satellite DNA of soybean is a 92-base-pairs tandem repeat. Theor Appl Genet 90:621-626

Kollipara KP, Singh RJ, Hymowitz T (1997) Phylogenetic and genomic relationships in the genus Glycine Willd. based on sequences from the ITS region of nuclear rDNA. Genome 40:57-68

Kopecky D, Lukaszewski AJ, Dolezel J (2008) Cytogenetics of festulolium (Festuca X Lolium hybrids). Cytogenet Genome Res 120:370-383

Krishnan P, Sapra VT, Soliman KM, Zipf A (2001) FISH mapping of the 5 S and 18S-28S rDNA loci in different species of Glycine. J Hered 92:295-300

Kulikova O, Geurts R, Lamine M, Kim DJ, Cook DR, Leunissen J, de Jong H, Roe BA, Bisseling $T$ (2004) Satellite repeats in the functional centromere and pericentromeric heterochromatin of Medicago truncatula. Chromosoma 113:276-283

Lam HM, Xu X, Liu X, Chen W, Yang G, Wong FL, Li MW, He W, Qin N, Wang B, Min J, Guo X, Murat F, Ham BK, Zhang Z, Gao S, Huang M, Xu Y, Zhong S, Bombarely A, Mueller LA, Zhao H, He H, Zhang Y, Zhang Z, Huang S, Tan T, Pang E, Lin K, Hu Q (2010) Resequencing of 31 wild and cultivated soybean genomes identifies patterns of genetic diversity and selection. Nat Genet 42:1053-1059

Lim KY, Skalicka K, Koukalova B, Volkov RA, Matyasek R, Hemleben V, Leitch AR, Kovarik A (2004) Dynamic changes in the distribution of a satellite homologous to intergenic 26-18S rDNA spacer in the evolution of Nicotiana. Genetics 166:1935-1946

Lin JY, Jacobus BH, SanMiguel P, Walling JG, Yuan Y, Shoemaker RC, Young ND, Jackson SA (2005) Pericentromeric regions of soybean (Glycine max L. Merr.) chromosomes consist of retroelements and tandemly repeated DNA and are structurally and evolutionarily labile. Genetics 170:1221-1230

Maluszynska J, Heslopharrison JS (1993) Molecular cytogenetics of the genus Arabidopsis : in situ localization of rDNA sites, chromosome numbers and diversity in centromeric heterochromatin. Annal Bot 71:479-484

Morgante M, Jurman I, Shi L, Zhu T, Keim P, Rafalski JA (1997) The STR120 satellite DNA of soybean: organization, evolution and chromosomal specificity. Chromosome Res 5:363-373

Mudge J, Cannon S, Kalo P, Oldroyd G, Roe B, Town C, Young N (2005) Highly syntenic regions in the genomes of soybean, Medicago truncatula and Arabidopsis thaliana. BMC Plant Bio 5:15

Newell CA, Hymowitz T (1975) Glycine canescens F. J. Herm. A wild relative of soybean Crop Sci 15:879-881

Newell CA, Hymowitz T (1983) Hybridization in the Genus Glycine Subgenus Glycine Willd (Leguminosae, Papilionoideae). Am J Bot 70:334-348

Pagel J, Walling JG, Young ND, Shoemaker RC, Jackson SA (2004) Segmental duplications within the Glycine max genome revealed by fluorescence in situ hybridization of bacterial artificial chromosomes. Genome 47:764-768 
Palmer RG, Newhouse KE, Graybosch RA, Delannay X (1987) Chromosome structure of the wild soybean-Accessions from China and the Soviet Union of Glycine soja Sieb. \& Zucc. J Hered 78:243-247

Pedrosa-Harand A, de Almeida CCS, Mosiolek M, Blair M, Schweizer D, Guerra M (2006) Extensive ribosomal DNA amplification during Andean common bean (Phaseolus vulgaris L.) evolution. Theor Appl Genet 112:924-933

Pinkel D, Straume T, Gray JW (1986) Cytogenetic analysis using quantitative, high-sensitivity, fluorescence hybridization. Proc Nat Acad Sci USA 83:2934-2938

Raskina O, Belyayev A, Nevo E (2004a) Activity of the En/Spm-like transposons in meiosis as a base for chromosome repatterning in a small, isolated, peripheral population of Aegilops speltoides Tausch. Chromosome Res 12:153-161

Raskina O, Belyayev A, Nevo E (2004b) Quantum speciation in Aegilops: Molecular cytogenetic evidence from rDNA cluster variability in natural populations. Proc Nat Acad Sci USA 101:14818-14823

Raskina O, Barber JC, Nevo E, Belyayev A (2008) Repetitive DNA and chromosomal rearrangements: speciation-related events in plant genomes. Cytogenet Genome Res 120:351-357

Ratnaparkhe MB, Singh RJ, Doyle JJ (2011) Glycine. In: Kole C (ed) Wild crop relatives: genomic and breeding resources: legume crops and forages. Springer, New York, pp 83-116

Schlueter J, Lin J-Y, Schlueter S, Vasylenko-Sanders I, Deshpande S, Yi J, O'Bleness M, Roe B, Nelson R, Scheffler B, Jackson S, Shoemaker R (2007) Gene duplication and paleopolyploidy in soybean and the implications for whole genome sequencing. BMC Genom 8:330

Schmutz J, Cannon SB, Schlueter J, Ma J, Mitros T, Nelson W, Hyten DL, Song Q, Thelen JJ, Cheng J, Xu D, Hellsten U, May GD, Yu Y, Sakurai T, Umezawa T, Bhattacharyya MK, Sandhu D, Valliyodan B, Lindquist E, Peto M, Grant D, Shu S, Goodstein D, Barry K, Futrell-Griggs M, Abernathy B, Du J, Tian Z, Zhu L, Gill N, Joshi T, Libault M, Sethuraman A, Zhang X-C, Shinozaki K, Nguyen HT, Wing RA, Cregan P, Specht J, Grimwood J, Rokhsar D, Stacey G, Shoemaker RC, Jackson SA (2010) Genome sequence of the palaeopolyploid soybean. Nature 463:178-183

Schubert I, Wobus U (1985) In situ hybridization confirms jumping nucleolus organizing regions in Allium. Chromosoma 92:143-148

Sebolt AM, Shoemaker RC, Diers BW (2000) Analysis of a quantitative trait locus allele from wild soybean that increases seed protein concentration in soybean. Crop Sci 40:1438-1444

Sherman-Brotles S, Bombarely A, Powell AF, Doyle JL, Egan AN, Coate JE, Doyle JF (2014) The wild side of a major crop-Soybean's perennial cousins from down under. Amer. J. Bot. 101:1651-1665

Shi L, Zhu T, Morgante M, Rafalski JA, Keim P (1996) Soybean chromosome painting: A strategy for somatic cytogenetics. J Hered 87:308-313

Shoemaker RC, Polzin K, Labate J, Specht J, Brummer EC, Olson T, Young N, Concibido V, Wilcox J, Tamulonis JP, Kochert G, Boerma HR (1996) Genome duplication in soybean (Glycine subgenus soja). Genetics 144:329-338

Singh RJ, Hymowitz T (1985) The genomic relationships among six wild perennial species of the genus Glycine subgenus Glycine Willd. Theor Appl Genet 71:211-230
Singh RJ, Hymowitz T (1987) Taxonomy and speciation. Wilcox, Soybeans: Improvements, Production, and Uses. Agronomy Monograph, pp 23-48

Singh RJ, Hymowitz T (1988) The genomic relationship between Glycine max (L.) Merr. and G. soja Sieb. and Zucc. as revealed by pachytene chromosome analysis. Theor Appl Genet 76:705-711

Singh RJ, Kim HH, Hymowitz T (2001) Distribution of rDNA loci in the genus Glycine Willd. Theor Appl Genet 103:212-218

Srivastava AK, Schlessinger D (1991) Structure and organization of ribosomal DNA. Biochimie 73:631-638

Stupar RM, Song JQ, Tek AL, Cheng ZK, Dong FG, Jiang JM (2002) Highly condensed potato pericentromeric heterochromatin contains rDNA-related tandem repeats. Genetics 162:1435-1444

Tateishi Y, Ohashi H (1992) Taxonomic studies on Glycine of Taiwan. J Jap Bot 67:127-147

Tek AL, Kashihara K, Murata M, Nagaki K (2010) Functional centromeres in soybean include two distinct tandem repeats and a retrotransposon. Chromosome Res 18:337-347

Thseng FS, Tsai SJ, Abe J, Wu ST (1999) Glycine formosana Hosokawa in Taiwan: pod morphology, allozyme, and DNA polymorphism. Bot Bull Acad Sin 40:251-257

Tindale M, Craven L (1988) Three new species of Glycine (Fabaceae: Phaseolae) from north-western Australia, with notes on amphicarpy in the genus. Aust Syst Bot 1:399-410

Tsai YC (2006) Study on phylogenetic relationship of Glycine species collected in Taiwan. Doctoral Dissertation, National Taiwan University

Tsai YC, Hsing YIC, Chung Cl, Hsieh JS (2001) Wild soybean and its relatives collected in Taiwan. Chinese Agro J 11:217-230

Ungerer MC, Strakosh SC, Zhen Y (2006) Genome expansion in three hybrid sunflower species is associated with retrotransposon proliferation. Curr Biol 16:R872-R873

Vahedian M, Shi L, Zhu T, Okimoto R, Danna K, Keim P (1995) Genomic organization and evolution of the soybean SB92 satellite sequence. Plant Mol Biol 29:857-862

Varshney RK, Sigmund R, Börner A, Korzun V, Stein N, Sorrells ME, Langridge P, Graner A (2005) Interspecific transferability and comparative mapping of barley EST-SSR markers in wheat, rye and rice. Plant Sci 168:195-202

Vindelov LL, Christensen IJ, Nissen NI (1983) Standardization of high-resolution flow cytometric DNA analysis by the simultaneous use of chicken and trout red blood cells as internal reference standards. Cytometry 3:328-331

Volkov RA, Borisjuk NV, Panchuk II, Schweizer D, Hemleben V (1999) Elimination and rearrangement of parental rDNA in the allotetraploid Nicotiana tabacum. Mol Biol Evol 16:311-320

Walling JG, Shoemaker R, Young N, Mudge J, Jackson S (2006) Chromosomelevel homeology in paleopolyploid soybean (Glycine max) revealed through integration of genetic and chromosome maps. Genetics 172:1893-1900

Weidner S, Becker A, Bonilla I, Jaenicke S, Lloret J, Margaret I, Puhler A, RuizSainz JE, Schneiker-Bekel S, Szczepanowski R, Vinardell JM, Zehner S, Gottfert M (2012) Genome sequence of the soybean symbiont Sinorhizobium fredii $\mathrm{HH} 103$. J Bacteri 194:1617-1618

\section{Submit your manuscript to a SpringerOpen ${ }^{\odot}$ journal and benefit from:}

- Convenient online submission

$\checkmark$ Rigorous peer review

- Immediate publication on acceptance

- Open access: articles freely available online

- High visibility within the field

- Retaining the copyright to your article

Submit your next manuscript at $>$ springeropen.com 